\title{
Una Reflexión Filosófica de la Dinámica Histórica de los Derechos Humanos
}

\author{
Alejandro Rosillo Martínez'
}

\section{Resumen}

Este artículo parte de la afirmación de que la narración hegemónica sobre la dinámica histórica de los derechos humanos tiene como fundamento, explícito o implícito, la filosofía ilustrada de la historia. Desde la Filosofía de la Liberación se critica esta concepción, y se considera que existen diversas alturas procesales donde, desde diferentes racionalidades y realidades, se generan demandas y reivindicaciones de las comunidades de victimizados en búsqueda de posibilitar la producción, reproducción y desarrollo de su vida. La dinámica histórica de los derechos no responde a generaciones que se complementan entre sí, ni a la expansión de la racionalidad interna de un concepto, sino a la posibilitación y generación de capacidades que la praxis histórica de liberación de los pueblos pueda dar de sí.

Palabras-clave: Derechos humanos. Filosofía de la historia. Liberación. Dinámica histórica. Posibilidades.

\footnotetext{
${ }^{1}$ Doctor en el Programa de Estudios Avanzados en Derechos Humanos de la Universidad Carlos III de Madrid, con la tesis "Los derechos humanos desde el pensamiento latinoamericano de la liberación”. Master en Estudios Avanzados en Derechos Humanos de la Universidad Carlos III de Madrid, con la tesina "La filosofía de la realidad histórica de Ignacio Ellacuría y los derechos humanos". Premio Extraordinario del Máster Universitario en Estudios Avanzados en Derecho Humanos, correspondiente a la promoción 2007/2008, otorgado por resolución de la Vicerrectora de Postgrado y Calidad, de la Universidad Carlos III de Madrid. Abogado. Facultad de Derecho de la Universidad Autónoma de San Luis Potosí. arosillo@gmail.com.
} 


\title{
A PHILOSOPHICAL REFLECTION OF HISTORICAL DYNAMICS OF HUMAN RIGHTS
}

\begin{abstract}
This article is based on the affirmation that the hegemonic narrative about the historical dynamics of human rights is founded, explicitly or implicitly, on the illustrated philosophy of history. From the Philosophy of Liberation is criticized this conception, and it is considered that there are various procedural stage where from different rationalities and realities are generated the demands and the claims of victimized communities seeking to enable the production, reproduction and development of life. The historical dynamics of rights does not respond to generations that complement each other or to the expansion of the internal logic of a concept, but the possibilitation and generation of capabilities that the historical praxis of liberation generates.
\end{abstract}

Keywords: Human rights. Philosophy of history. Liberation. Historicaldynamics. Possibilities.

\section{UMA REFLEXÃO FILOSÓFICA DA DINÂMICA HISTÓRICA DE DIREITOS HUMANOS}

\section{Resumo}

Este artigo parte da afirmação de que a narração hegemônica sobre a dinâmica histórica dos direitos humanos tem como fundamento, explícito ou implícito, a Filosofia lluminista da História. Desde a Filosofia da Libertação se critica esta concepção, e se considera que existem diversas alturas processuais onde, desde diferentes racionalidades e realidades, geram demandas e reivindicações das comunidades de vitimizados na busca de possibilitar a produção, reprodução e desenvolvimento de sua vida. A dinâmica histórica dos direitos não responde a gerações que se complementam entre si, nem a expansão da racionalidade interna de um conceito, mas a possibilidade e geração de capacidades que a práxis histórica de libertação dos povos pode dar de si.

Palavras-chave: Direito humanos. Filosofia da História. Libertação. Dinâmica histórica. Possibilidades.

\section{Sumário}

1 Introducción. 2. La concepción teleológica de la filosofía de la historia. 3. La lectura teleológica y eurocéntrica de la historia de derechos humanos. 3.1. Algunas lecturas sobre la historia de derechos humanos. 3.2. La Necesidad de Otra Filosofía de la Historia. 4. El Análisis de la Historia en la Filosofía de la Liberación. 4.1. La Historia Como Transmisión Tradente. 4.2. La Historia Como Actualización de Posibilidades. 4.3. La Historia como Proceso Creacional de Posibilidades. 5. Conclusión. Referencias 


\section{INTRODUCCIÓN}

Cuando se piensa "derechos humanos" no es usual hacerlo desde la filosofía de la historia. Cierto es que esta rama de la filosofía no goza de buena reputación en tiempos actuales, al ser considerada una reflexión lejana a los hechos. No obstante, a pesar de su aparente negación, el pensamiento hegemónico, en función de su universalismo abstracto y etnocentrismo, no pocas veces comprende la historia de los derechos desde una concepción teleológica e idealista. Esto nos da la pauta para sostener la importancia de pensarlos sin negar una concepción de la historia; de hecho, como veremos, a pesar de su rechazo, la concepción hegemónica no puede evitarlo.

La manera en que la Filosofía de la Liberación (FL) repiensa derechos humanos afecta la concepción que de la historia se tiene. Una historiografía de la liberación busca recuperar experiencias que han sido invisibilizadas y desperdiciadas por la razón hegemónica e indolente de la Modernidad (Santos, 2000). Para esto, además de los presupuestos que en otros espacios hemos desarrollado (Rosillo Martínez, 2010), es necesaria una concepción diferente de la historia, que reconozca la materialidad de tal manera que supere las visiones idealistas y teleológicas. Además, una fundamentación de derechos humanos basada en las necesidades para la producción y reproducción de vida requiere de un concepto de historia que les sea complementaria, pues las visiones idealistas y teleológicas desconocen la corporalidad del ser humano, y se les da un uso ideológico. De ahí que sea necesario otra concepción de historia que critique y supere estas compresionesque se basan en un pensamiento idealista, simplificante y que responden a un universalismo abstracto y etnocéntrico.

\section{LA CONCEPCIÓN TELEOLÓGICA DE LA FILOSOFÍA DE LA HISTORIA}

La concepción teleológica tiene sus orígenes en la filosofía occidental en Agustín de Hipona, quien presenta la historia como un gran proceso de salvación que inicia con el pecado original y concluye en el juicio final. 
El conocimiento de los hechos históricos puede versar sobre la existencia y desarrollo de los distintos imperios; sin embargo, los principios que nos permiten interpretar estos hechos no preceden de sí mismos, sino que los acontecimientos temporales deben ser juzgados siempre a la luz de la revelación cristiana. En la Ciudad de Dios, Agustín de Hipona no realiza una obra histórica, sino una filosofía de la historia que tiene como finalidad discernir el significado moral y espiritual de los acontecimientos históricos. Gilber Rist (2002) considera que la originalidad agustiniana - que será recogida y explotada en un futuro - sobre una filosofía del "desarrollo", se basa en tres factores: (a) La filosofía de la historia agustiniana atañe al conjunto del género humano. (b) La relevancia de los acontecimientos históricos particulares se establece por su relación con el plan de Dios. La historia concreta se somete a la filosofía de la historia. (c) La historia obedece a una necesidad, a pesar de sus apariencias caóticas.

Secularizando y colocándoles bases "racionales", la filosofía de la historia de la Modernidad recoge en parte estos factores del pensamiento agustiniano. Esa filosofía, surgida a partir del pensamiento de Herder y Kant y conducida a su máxima expresión por Hegel, concibe la historia como desarrollo, como un desenvolvimiento de lo que al principio potencialmente está en la naturaleza del ser humano, en el plan de la Naturaleza o en la lógica del Espíritu Absoluto. Si bien estas concepciones de la historia quisieron guiar la emancipación del ser humano, varios de estos autores terminaron desconfiando del ser humano y buscaron otra instancia que asegurara el progreso de la historia. La novedad histórica desaparece y también la responsabilidad ética frente al progreso. Por eso podemos afirmar que la visión teleológica de la historia ha condicionado la mayor parte de la filosofía de la historia.

Kant abordó el tema de la historia por las cuestiones morales que se planteaba. Tiene presente un progreso ético al que se somete la historia, por lo que hay una justificación moral interior en ella. Todo es compren- 
sible y lógico desde el momento en que justifica y cimienta la constitución del estado que impulsa la naturaleza. Por tanto, el ser humano posee las potencialidades naturales, algunas de las cuales apuntan al uso de su razón y se deben desarrollar complemente en la especie y no en los individuos. Así, la historia es el progresivo despliegue de disposiciones de la razón contenidas en los seres humanos. Estas potencialidades no pueden desarrollarse de manera individual y por lo tanto es necesaria la historia. La Naturaleza, entonces, se sirve para desarrollar las disposicionesracionales de la especie mediante un antagonismo de dichas disposiciones en la sociedad. La antropología negativa de Kant (1997) se hace presente; tras los conflictos humanos, el proyecto de la Naturaleza viene a cubrir el vacío que deja el ser humano.

Por su parte, Hegel (1946) es el primer filósofo que celebra de manera optimista y eufórica, la idea de que la historia universal va del Oriente al Occidente ${ }^{2}$, comprendiendo a Europa como el fin de la historia universal, y considerándola como el centro y el fin del mundo antiguo. Además, para él, la Europa del sur ha dejado de ser la portadora del Espíritu y el corazón de Europa se localiza en los países germano-anglosajones del norte. La filosofía de la historia es la consideración reflexiva de ésta, y es parte de la filosofía del Espíritu. En efecto, que la razón actúa en la historia es una proposición demostrada por la lógica. La historia mundial es un proceso racional, por el cual el Espíritu llega a una conciencia real de sí mismo como libertad; por tanto, es el progreso de la conciencia de la libertad. Pero esta conciencia se obtiene tan sólo a través de la mente humana; de ahí que sea el proceso por el cual el espíritu del mundo llega a explicitar la conciencia que tiene de sí mismo como libre. (Hegel, 1997).

2 "La historia universal va del Oriente al Occidente. Europa es absolutamente el Fin de la Historia Universal. Asia es el comienzo” (Hegel, 1946, p. 207). 
A partir de la conciencia humana, Hegel denomina como totalidad a aquélla que es la conciencia de que todo forma parte del saber y de que toda la realidad es un momento del Absoluto. Así, toda la realidad termina por ser comprendida como un momento de un sujeto, un saber o una conciencia absoluta. Todo el universo y los seres humanos son parte del absoluto, de un sujeto universal que ha de ser racional, porque, por definición, todo sujeto y toda conciencia son algo racional. El espíritu del ser humano y la naturaleza son dos momentos del absoluto. Todo lo real no es más que el desarrollo, el despliegue, del Absoluto, pues todo lo real es racional y lo racional es real.

La historia es develación, despliegue dialéctico de una razón y de un logos. La teleología aparece al afirmar que la historia no es otra cosa que la progresiva develación o despliegue del Espíritu, un proceso que partiendo de la naturaleza ha de alcanzar el Espíritu Absoluto: “...la historia es el despliegue - necesario en base solamente al concepto de su libertad- de los momentos de la razón, de su conciencia de sí y de su libertad; es la exégesis y la realización del Espiritu universal" (Hegel, 2004, p. 277). La racionalidad de la historia consiste en que nos muestra la voluntad del Espíritu de volver en sí mismo a través de las contradicciones (dialéctica). El Absoluto determinaría rigurosamente todos los cambios y todas las fases por las que van pasando los pueblos. El individuo concreto y real sería entonces un ser meramente pasivo, limitado a desempeñar el papel que la razón le ha concedido. En la historia no habría más que el desarrollo de una lógica cerrada impuesta a todos los seres humanos.

La filosofía de la historia de Hegel busca mostrar cómo el espíritu absoluto toma cuerpo en la vida práctica, cultural y política de la humanidad en su historia. Por eso la historia humana es la historia de la manifestación progresiva del Espíritu; se trata de "un progresivo despliegue y surgimiento de nuevas formas de concebir la realidad que son luego reemplazadas por la refutación que ejercen otras sobre ellas, que se van con- 
siderando más adecuadas” (Brauer, 2005, p. 106). El Espíritu va tomando poco a poco conciencia de sí mismo, hasta llegar a una plena reconciliación que para Hegel tendrá lugar en el momento en que la cultura humana llegue a su máxima plenitud: y esto es lo que sucede justamente, a su modo de ver, en la filosofía del idealismo alemán.

En la historia del mundo los sujetos que intervienen son los pueblos, las totalidades son Estados. Pero para Hegel, el estado no es sólo el concepto jurídico, sino más bien una totalidad que existe en y a través de sus miembros, aunque no es idéntica a cualquier conjunto de ciudadanos que existen en un momento y lugar determinados, y que otorga forma concreta al espíritu y cultura de un pueblo o nación. Esto es porque el espíritu nacional existe sólo en y a través del estado. Por eso, como hemos dicho, la historia es el progreso de la conciencia de libertad donde los protagonistas son los Estados. El Espíritu se despliega a través del estado; en ambos hay una misma autodeterminación teleológica. En su avance hacia una completa y explícita autoconciencia, toma la forma de manifestaciones limitadas y unilaterales de sí mismo, de los diversos espíritus nacionales. Hegel supone que en cualquier época hay una nación determinada que representa de forma especial el desarrollo del Espíritu, y sólo ocupa ese puesto una vez en la historia.

La historia universal es el desenvolvimiento del Espíritu, en un proceso que lo lleva a sus formas supremas; son las fases a través de las cuales el Espíritu alcanza su verdad y la conciencia de sí mismo (Hegel, 1946). Las formas de estas fases son los espíritus de los pueblos históricos, las determinaciones y su vida moral, de su constitución, de su arte, de su religión y de su ciencia. En el mundo oriental fueron el despotismo y la esclavitud la regla general, y por tanto la libertad se limitaba a un solo individuo. En el mundo grecorromano, aunque se conservó la institución de la esclavitud, se extendió el campo de la libertad a todos los ciudadanos. Entonces, las naciones germánicas de la Europa moderna terminaron el 
proceso de libertad universal. Para Hegel, fueron estos pueblos los que, bajo la influencia del cristianismo, llegaron a tener conciencia por primera vez de que el hombre es libre por el simple hecho de serlo. Pero si bien este principio fue siempre reconocido por el cristianismo, no quiere decir que encontrara en todo momento su expresión en las leyes, la organización gubernamental y política y las instituciones. La conciencia interior de la libertad del espíritu hubo de objetivarse explícitamente, y es en esto donde Hegel atribuye un papel preponderante a los pueblos germánicos.

Desde la perspectiva de la FL, el concepto de historia de la filosofía hegeliana es destacable por las consecuencias que acarrea para la exterioridad. Si, como hemos dicho, la FL opta por el lugar-que-da-verdad y por ser un pensamiento que se construye desde la periferia, entonces su postura ante esta idea desarrollista de la historia debe ser critica, para mostrar el uso ideologizado que se le da en contra de los pueblos sometidos al centro hegemónico mundial.

Si la historia es un desarrollo racional del Espíritu, entonces en el principio ya está contenido todo lo que va a ser su evolución a lo largo de los siglos. Por eso, en la historia no se inventaría nada, no habría novedad, ni los seres humanos tendrían posibilidad de intervenir responsablemente en la misma con su praxis, sino que un destino racional e inexorable estaría ya predeterminando todo lo que va a suceder en el presente y en el futuro. De ahí que se justifique la explotación y el colonialismo; la destrucción de un pueblo a costa de otro que se considera culturalmente superior.

\section{LA LECTURA TELEOLÓGICA Y EUROCÉNTRICA DE LA HISTORIA DE DERECHOS HUMANOS}

Hemos descrito dos filosofías que son paradigmáticas en cuanto a la comprensión de la historia en la Modernidad hegemónica, y que pueden describirse como teleológicas e idealistas. El fin de la historia se convierte 
en un ideal ético concretado en la realización de un estado ideal, predeterminado explícita o implícitamente de antemano; se coloca el fin de la historia en una realidad supra humana que para su logro parecería ser permitido pasar por encima de toda individualidad personal.

Hoy día es difícil suponer que alguien asumiría expresamente una filosofía de la historia con estas características. No obstante, esta visión está muy presente, aún sin declararlo de manera explícita, en el sentido común y en el pensamiento dominante de Occidente (González, 2005). Así, por ejemplo, las lecturas hegemónicas sobre la historia de los derechos humanos contienen elementos de esas filosofías teleológicas de la historia, y que si bien algunas buscan evitarlas, al no asumir un concepto de la historia diferente terminan encasillados dentro de la misma perspectiva; convierten a "derechos humanos" en un concepto eurocéntrico.

Samir Amin señala la implicación en una teleología como una de las características del eurocentrismo, consistente en que "toda la historia de Europa preparaba necesariamente el nacimiento del capitalismo en la medida en que el cristianismo, considerado como religión europea, supuestamente fue más favorable que las demás religiones a la aparición del individuo y al ejercicio de su capacidad de dominar la naturaleza” (Amin, 1989, p. 83). De ahí que el eurocentrismo lleve aparejada una concepción teleológica de la historia, pues de una y otra forma, para que el mundo sea "más humano", "se desarrolle" o "progrese" habrá de "occidentalizarse”, y ello implica, como señala Wallerstein, imponer "a todos la adopción de las recetas que determinan la superioridad europea: la libertad de empresa y el mercado, el laicismo y la democracia electoral pluralista”(Amin, 1989, p. 103), a lo que nosotros añadiríamos "los derechos humanos".

La manera tradicional de narrar la dinámica histórica de derechos humanos es una expresión de esta teleología eurocéntrica, y ésta es una de las características que con mayor claridad muestra la manera en que 
la filosofía de la historia de la Modernidad hegemónica sigue presente, aunque no sea de manera expresa, en gran parte del pensamiento contemporáneo. Pongamos unos ejemplos.

\subsection{Algunas Lecturas Sobre la Historia de Derechos Humanos}

Existe una extensa bibliografía respecto a la historia de los derechos humanos, aunquela mayoría se inserta en una visión teleológica eurocéntrica. Analizaremos a dos autores, que en cierta forma nos muestran diferentes maneras en que se hace presente dicha concepción de la historia.

Es importante insistir en que la filosofía de la historia idealista y teleológica no se presenta de manera explícita en estos autores; al contrario, encontramos afirmaciones donde buscan desligarse de esta visión. No obstante, a pesar de su desvinculación expresa, en sus discursos se siguen detectando resabios de la misma. Por eso, nuestro análisis no busca descalificar de manera total la lectura de la dinámica histórica de los derechos humanos que realizan estos autores, sino evidenciar la persistencia de una visión teleológica e idealista.

Enrique Pérez Luño (2005, p. 132) ha asumido en su pensamiento la idea de las generaciones de derechos humanos. Si bien se desmarca expresamente de una filosofía de la historia idealista y teleológica, al afirmar que "[e]s evidente que el proceso de positivización de los derechos humanos no ha sido lineal”, por otro lado, encontramos diversos elementos que muestran lo contrario. El autor habla de una "línea evolutiva" y de una "mutación histórica" de los derechos que ha determinado la aparición de sucesivas "generaciones” de derechos (Pérez Luño, 1991, p. 205). Su análisis deja a un lado las praxis concretas de liberación relacionadas con derechos humanos, y su dinámica histórica la concibe como una dialéctica 
entre el desarrollo de técnicas e ideas: “[L]a positivización (...) [es] el producto de una dialéctica constante entre el progresivo desarrollo en el plano técnico de los sistemas de positivación, y el paulatino afirmarse en el terreno ideológico de las ideas de la libertad y la dignidad humanas” (Pérez Luño, 2005, p. 111). Señala, en este sentido, que desde la perspectiva ideológica la afirmación de la libertad personal frente al poder ha sido una constante en el "devenir histórico" de la humanidad, hasta llegar a su exigencia en el orden jurídico-positivo. Este desarrollo lo describe de manera semejante a como Hegel lo hace respecto al Espíritu: en los pueblos orientales de la antigüedad se dan organizaciones políticas que desconocen los derechos personales, y se apoya explícitamente en Hegel, quien "caracterizó certeramente los imperios orientales del mundo antiguo como regímenes patriarcales en los que 'el sujeto no ha adquirido todavía su derecho y lo que reina es más bien un orden ético inmediato y desprovisto de leyes” (Pérez Luño, 2005, p. 111). Luego, por supuesto, en Grecia "brota" el principio de individualidad que progresivamente va impregnando las instituciones sociales y desemboca en la Atenas del siglo $5^{\circ}$ a.C. En el fondo del pensamiento del autor sigue presente la concepción potenciaacto de la filosofía de la historia teleológica e idealista. Parecería que las condiciones materiales no tienen que ver con los procesos de liberación, y las ideas brotan de alguna instancia humana que ya las contenía de manera potencial y que sólo requería el paso de la historia para que se mostrasen en acto. En esta línea histórica, Roma supuso un avance decisivo en el perfeccionamiento técnico de la positividad jurídica; en ella se reconoce la libertad del ciudadano, aunque no estuvo suficientemente garantizada por el poder público. En la siguiente etapa, con el cristianismo, hay un reconocimiento de la personalidad moral, haciendo suyos los aportes del humanismo iusnaturalista estoico: “...la construcción técnico-jurídica de su positividad debida al derecho romano, junto con la progresiva decanta- 
ción ideológica del humanismo iusnaturalista clásico, luego cristianizado, fueron elementos de singular trascedencia para la sucesiva plasmación en documentos de los derechos humanos” (Pérez Luño, 2005, p. 113).

La positivización de los derechos humanos comienza, para Pérez Luño, en la Edad Media europea, a través de un establecimiento parcial de derechos en documentos jurídicos. Este liberalismo medieval es considerado como fermento del liberalismo moderno. No obstante, estos derechos se consideraban como patrimonio del individuo en su condición presocial, y entonces proviene la lucha proletaria de los derechos económicos y sociales. Por último, se da el proceso de internacionalización, donde la positivización de derechos humanos ha rebasado el ámbito del derecho interno para plantearse también como una exigencia del derecho internacional.

Pérez Luño (1991) asume y prolonga la línea histórica trazada por Hegel, y sustituye el Espíritu por “derechos humanos”. Aunque no declara el fin de la historia, sí la proyecta hacia el logro de una comunidad internacional como la pensada por Kant en la Paz perpetua. La dinámica histórica es presentada de manera teleológica e idealista: las "generaciones" se asumen como un modelo histórico racional y lineal, donde unos derechos tan sólo complementan a los anteriores (Pérez Luño, 1991). En efecto, no es la praxis de liberación de las víctimas de los sistemas - sistemas reforzados por y fundamentados en los derechos vigentes - los que generan "nuevos derechos", sino tan sólo una expansión de los derechos humanos, un paso de la potencia al acto. De ahí que sea fácil invisibilizar las praxis de liberación de sujetos concretos por "valores” y declarar que cada generación corresponde a un valor abstracto.

La exclusión de la mayor parte de la humanidad del disfrute de los derechos “de primera generación”, en muchas ocasiones provocada por el colonialismo y el tráfico de esclavos realizados por los propios sujetos que disfrutaban de esos derechos, no es visto como expresión de un sistema 
económico que estaba en ascenso, sino como una mera cuestión de "consciencia”. Pérez Luño (1991, p. 216) afirma, en este sentido, que “[e]1 sujeto titular de los derechos de la primera generación carecía de una auténtica consciencia de carácter universal de los derechos humanos”.

En su análisis del dinamismo histórico de derechos humanos, Pérez Luño soslaya las limitantes que tiene para tal efecto la clasificación (o metáfora) de las generaciones. A pesar de ser una de las lecturas de la historia de derechos humanos más difundida, contiene una importante carga de ahistoricidad, de abstracción, que pasa por alto las condiciones materiales de la realidad histórica (Sánchez Rubio, 2010).

La visión de las "generaciones" está también afectada por el eurocentrismo: los derechos humanos se gestaron y se han desarrollado en Europa, ylas experiencias de liberación de otros pueblos no son tomadas en cuenta. Fuera de Europa, el autor sólo cita a las constituciones de India (1950) y de Argelia (1963), de las que considera, junto con otras generadas en países afectados por el proceso de descolonización, que se han tratado, "en muchos casos, de meras fórmulas de imitación cultural que no han tenido el debido reflejo en el orden práctico, debido generalmente a la falta de una estructura socio-económica que permitiera dar plena eficacia a los derechos sociales proclamados por la vía constitucional" (Pérez Luño, 2005 p. 125). La punta de lanza de la historia está en Occidente, en los países colonizadores, en la razón del centro del sistema-mundo; las praxis de liberación generadas en otros suelos, desde otras lógicas y racionalidades, y aún en contra de la expansión colonial de ese centro hegemónico, no son tomadas en cuenta para narrar el dinamismo histórico de derechos humanos.

En segundo lugar, abordemos el pensamiento de Gregorio PecesBarba, que llama "los modelos de evolución histórica de los derechos fundamentales”. Su concepción de la historia no se presenta con la misma claridad que en el ejemplo anterior; este autor realiza diversas afirma- 
ciones que acercan su reflexión a una concepción distinta de la historia, pero su hilo principal de argumentación muestra que veladamente sigue presente la perspectiva teleológica e idealista.

El modelo propuesto por Peces-Barba tiene, según declara él mismo, el objetivo de buscar una comprensión integral de los derechos y superar ciertos reduccionismo. Lo hace de tres maneras: caracterizando los modelos iniciales de los derechos; siguiendo la evolución histórica de ellas hasta la actualidad; y estudiando los contenidos y el sentido que tienen las aportaciones liberal, democrática y socialista.

Peces Barba identifica tres - y sólo tres - modelos iniciales de derechos fundamentales. Desde el siglo 27 señala que se puede hablar de un modelo inglés y desde el 18 de los modelos americano y francés. En cada uno de ellos, encuentra algunas características propias. Afirma que el modelo inglés está vinculado a la historia, y arranca de la evolución del constitucionalismo medieval y del viejo y buen derecho de los ingleses; el americano lo considera un modelo mixto, que parte de los textos de las colonias en el siglo $17 \mathrm{y}$ de la influencia de las fundamentaciones del iusnaturalismo racionalista y pasa de los derechos históricos a los derechos naturales en los textos de la independencia; y por último, considera que el modelo francés rechaza su vinculación con el constitucionalismo histórico de las Leyes fundamentales de la monarquía y parte de un racionalismo laico (Peces-Barba, 1999).

Una vez establecidos los inicios de los derechos, señala que esos modelos "han seguido hasta nuestros días un proceso de evolución, cuya descripción debe ser tenida en cuenta para la búsqueda del por qué de los derechos" (Peces-Barba, 1999, p. 154). En este punto es cuando se muestra con mayor claridad la perspectiva teleológica e idealista, pues afirma que "[e]n muchos casos, esa evolución ya estaba apuntada en los mismos [derechos], como un embrión a desarrollar o una contradicción a superar" (Peces-Barba, 1999, p. 154). Es decir, que en la idea de los derechos ya se 
encontraba preestablecido de antemano su desarrollo histórico; sólo era necesario que pasara a la realidad. No obstante, como decíamos, PecesBarba intenta presentar su modelo como ajeno a una teleología idealista, y por eso señala lo siguiente:

No queremos decir con esto que la historia sea sólo el comprobante de una realidad nuclear inicial que tuviese necesariamente que desplegarse como lo hizo, ni que la positivación, generalización e internacionalización se pudiesen prever antes de que se iniciasen. Ese mecanismo es ajeno a nuestro pensamiento. Sólo queremos llamar la atención sobre el simple hecho de que la racionalidad inicial se desplegó y se completó al hilo de la historia, o si se quiere, el consenso inicial se completó con el consenso de los hombres a través del tiempo, sin que estuviese predeterminado el sentido de ese consenso, sino que se construyó sobre la marcha (1999, p. 155).

En el texto citado, el autor niega la existencia de un despliegue necesario, es decir, de un despliegue que se pudiese prever su realización a priori. Y esto es, básicamente, porque reconoce la importancia de la intervención de la praxis humana en el dinamismo de la historia; por eso, no establece el avance de derechos humanos en una instancia ajena al ser humano. No obstante, si los derechos humanos seguían progresando o desarrollándose debían, entonces sí, seguir la teleología generada por su racionalidad. Por tanto, la praxis humana se encontraba encerrada o condicionada a continuar con esa racionalidad para que "realmente" se generaran los derechos. De ahí que el proceso de positivización era algo necesario, propio de la propia racionalidad de la idea, si los "derechos" querían constituirse en tales y no quedarse en premisas morales. A partir del siglo 19, señala el autor, la positivización "se considera una condición esencial para la existencia de los derechos con eficacia social y no se concibe una implementación de ellos al margen de la positivización” (PecesBarba, 1999, p. 159). 
La praxis humana está subordinada a una teleología que nace de la propia racionalidad del concepto de derechos humanos. Si bien aquélla es fundamental para el desarrollo de estos, se encuentra sometida a la racionalidad del concepto, con el fin de que el embrión pueda desarrollarse o la contradicción sea superada. Como ejemplos de este embrión que se fue desarrollando, es decir, de este desenvolvimiento de la potencia al acto, señala el autor la positivización como derivación de los planteamientos iusnaturalistas racionalistas al centrar el paso del estado de naturaleza al de sociedad en el contrato social, y la justificación de la función soberana del poder de crear derecho. Considera que la generalización fue consecuencia de la dimensión igualitaria con la que lingüísticamente se formulan en la última fase del modelo americano y sobre todo en la Declaración francesa, cuando en el primer artículo se afirma que todos los hombres nacen y permanecen iguales y libres en derechos; este proceso "[s]upone la lucha por superarla contradicción entre esa afirmación y la realidad de algunos derechos no reconocidos, o disfrutados sólo por una minoría”(Peces-Barba, 1999, p. 154). Es decir, se afirma la existencia de una lucha con fundamentos idealistas, pues se basa en la superación de una contradicción del concepto con la realidad, y no en la lucha de los oprimidos por acceder a las condiciones materiales para la producción y reproducción de la vida, donde los conceptos están en función de la praxis.

El proceso de internacionalización también se da gracias a la racionalidad contenida en el concepto. Resalta Peces-Barba que "ya desde esos paradigmas iniciales parece que unos derechos naturales justificados por su propia racionalidad deben alcanzar una validez jurídica universal, por encima de las fronteras y que abarque a toda la toda la Comunidad Internacional” (1999, p. 154-155). Como parte del proceso de internalización, asume con claridad una postura teleológica. 
En su modelo de evolución de los derechos, Peces-Barba construye, aun sin quererlo, una visión lineal de la historia. Desde la aparición del concepto en cada uno de los tres modelos, se comienzan a generar procesos que de manera progresiva van desarrollando (desvelando) la racionalidad del concepto en la realidad. Señala que "[1]a combinación entre racionalidad e historicidad de los derechos aparece aquí muy plásticamente con estos tres rasgos [positivización, generalización e internacionalización], que suponen la realización histórica de un tenor racional de los derechos, formulado desde su origen pero inexistente en la realidad inicial de los mismos" (Peces-Barba, 1999, p. 155); no se niega la historia, pero ésta se desarrolla en virtud de la racionalidad.

Desde esta concepción lineal y progresista, las diversas ideologías también participan de la racionalidad de la historia de los derechos. En efecto, en cuanto a las influencias ideológicas, habla de una línea de tiempo donde se suceden el modelo liberal, el modelo democrático y el modelo socialista de derechos. Señala que "[e]1 modelo socialista de derechos humanos es el último en el tiempo”, y busca incorporar elementos igualitarios a la libertad y dejar a un lado las dimensiones con imposible contenido igualitario: su objetivo final es "extender a la clase trabajadora los beneficios de la revolución liberal” (Peces-Barba, 1999, p. 203).

Si los procesos de positivización, generalización e internacionalización responden a la expansión de la racionalidad de los derechos, en cambio el proceso de especificación, "rompe con esta línea y abre otro camino que no estaba, a mi juicio, presente en el ideario primitivo" (1999, p. 155). Es decir, las luchas de sectores específicos que desde sus distintas identidades exigen derechos no responden al avance de la racionalidad original de los derechos, y por lo tanto la especificación "es un avance del historicismo sobre el racionalismo y parte de la idea de considerar a los derechos más vinculados a las personas concretas de sus titulares. 
Se juzgan como relevantes algunas situaciones del genérico 'hombres' o 'ciudadanos', que exigen un tratamiento especial y que no se resuelven desde ese "homo iuridicus”' (1999, p. 181).

Considerar esta ruptura, más que reconocer la materialidad de la historia, muestra la perspectiva universalista e iluminista de este modelo de evolución. El autor no ve que la lucha identitaria por "nuevos derechos" no se reduce a una disputa entre el racionalismo y el historicismo, sino que pasa por el empoderamiento de víctimas a través de praxis de liberación provenientes de distintos sectores y racionalidades. Tan vinculados estaban los derechos a personas concretas tratándose de los revolucionarios del siglo 18I, como los derechos de los pueblos indígenas, de las mujeres, de los niños, de los jóvenes, de los homosexuales, etc. La diferencia estuvo en el discurso abstracto de la burguesía que colocó como universales sus valores y que denunció como enemigos de la humanidad a todo opositor. La concepción de la historia que está de fondo en este modelo impide que la crítica a la ideologización sea radical. El autor reconoce el uso ideologizado que los burgueses dieron a los derechos (1999, p. 162); no obstante, este uso “ocurrió en los orígenes del Estado liberal, y fue la conexión razón-historia, donde se desenvuelve el proceso de generalización, lo que permitió salir de la contradicción” (1999, p. 162); el progreso lineal de la historia ha posibilitado superar la ideologización, la cual ya no se da en virtud al proceso de generalización.

Por último, al igual que en la propuesta de Pérez Luño, este modelo de evolución es eurocéntrico. La única mención que se hace de la periferia del sistema-mundo es referente a la conferencia de "La conferencia de Berlín sobre África Central (1885) afirmará que 'el comercio de esclavos está prohibido por los poderes de acuerdo con los principios del Derecho Internacional reconocido por los poderes firmantes” (1999, p. 173). Es una aseveración desde la perspectiva del centro hegemónico que impone su voluntad a la periferia. Se trata de un acontecimiento histórico que el 
autor cita como parte del proceso de internacionalización: los derechos humanos se expanden del centro a la periferia. No ve en la libertad de los esclavos del África Central ni siquiera un proceso de generalización (ése es el propio de los obreros europeos), sino sólo un proceso de internacionalización; es decir, que la libertad de los seres humanos periféricos estuvo en función del "estado de madurez" logrado por Europa, dondesu consciencia fuera capaz de reconocer la libertad de los otros.

\subsection{La Necesidad de Otra Filosofía de la Historia}

¿Por qué es necesaria, desde la perspectiva de derechos humanos, una filosofía de la historia que rompa con el esquema clásico de potenciaacto? El interés de la FL respecto a la historia se encuentra en la relación que guarda con la fundamentación de derechos humanos. ${ }^{3}$ Una fundamentación basada en el sujeto vivo, práxico e intersubjetivo es incompatible con una concepción de la historia teleológica e idealista. Este tipo de visiones terminan soslayando la praxis humana, negando la intersubjetividad de los sujetos, y justificando la negación de la vida si la muerte del sujeto está en función del fin de la historia (2005).

La FL puede tomar, en parte, la crítica de la posmodernidad pero sin caer en un caos de arbitrariedad hermenéutica; en cambio, asume que la historia tiene dinamismos propios, que existen sentidos históricos reales aunque no estén predeterminados; y que el progreso no está asegurado y su abstracción genera la falacia desarrollista. Esto porque las

\footnotetext{
${ }^{3}$ Cabe señalar que no sólo la FL ha enfatizado la necesidad de una nueva comprensión de la historia. Boaventura de Sousa Santos ha señalado que es necesario reinventar el pasado para pensar en la transformación social y la emancipación; es necesario repensarlas a partir del pasado y de cara al futuro. Por eso critica las teorías clásicas del ahistoria en los siguientes términos: "La desvaloración del pasado y las hipótesis del futuro fueron comunes a las diversas teorías de la historia. El pasado fue visto como pasado y, por ello, incapaz de hacer su aparición, de irrumpir en el presente. Por el contrario, el poder de revelación y fulguración se trasladó al futuro" (Santos, 2005, p. 116).
} 
posibilidades que enfrenta la praxis humana no son meras "ocurrencias interpretativas”, sino que están ancladas en la realidad (González, 2005, p. 184). La fundamentación y la comprensión compleja de derechos humanos que asume la FL requieren de una concepción de la historia que supere la falacia desarrollista. El desarrollismo es una posición ontológica por la que se piensa que el "desarrollo" (o desarrollismo) que siguió Europa debe ser seguido miméticamente por todas las demás culturas.

La categoría del desarrollo o desarrollismo se hace presente en diversas lecturas de la dinámica histórica de los derechos humanos a través del eurocentrismo. Cabe señalar que, como afirma Amin, éste no es una teoría social acabada, pues no integra sus diferentes elementos en una visión global y coherente de la sociedad y de la historia; más bien es "un prejuicio que actúa como una fuerza deformante en las diversas teorías sociales propuestas. Ese prejuicio eurocéntrico echa mano de la reserva de elementos identificados, reteniendo uno y rechazando otro según las necesidades de la ideología del momento” (Amin, 1989, p. 87). De ahí que su superación, como "prejuicio" en la lectura histórica de derechos humanos, sea parte de la tarea crítica de la FL.

Una comprensión distinta de la historia debe evitar que derechos humanos se vuelvan -o sigan siendo- herramientas de neocolonialismo, explotación y opresión. La filosofía ilustrada de la historia no es compatible con el lugar social que la FL asume, que es la perspectiva del victimizado, del empobrecido y del oprimido por los sistemas. Vale la pena referirnos a la famosa tesis IX en "Sobre el concepto de historia" de Walter Benjamin (2008), donde utiliza al Angelus Novus del cuadro de Klee para denunciar cómo el progreso de la Modernidad invisibiliza a las víctimas que son su consecuencia y su costo (Mate, 2009. p. 165) Por eso, el concepto de historia que asuma la FL debe incluir y posibilitar la perspectiva de la víctima.

Aunado a lo anterior, sería imposible hablar de una Tradición Iberoamericana de Derechos Humanos (Rosillo Martínez, 2011) si la FL asumiera un concepto eurocéntrico de historia. Ya sea a través de un modelo de "gene- 
raciones" o de "procesos", los hechos acontecidos fuera de Europa no son considerados relevantes para la dinámica histórica de derechos humanos. Esto genera un desperdicio de la experiencia y una forma de leer el pasado que impide repensar las luchas de liberación en el presente. Por otro lado, la concepción teleológica e idealista de la historia desconoce la importancia de la praxis humana para la protección de derechos humanos. Al ubicar el avance de la historia en relación con una instancia supra-humana (el Espíritu, la racionalidad, etc.), se cae en la generación de "garantías trascendentales”. En este sentido, al abordar las garantías de una conceptualización idealizada y descontextualizada de los derechos humanos, Joaquín Herrera habla de la garantía trascendental. Ésta tiene relación con la existencia de un "bien” que está por encima de todo y desde el que es posible juzgar el contenido de la acción social. Pues bien, según esta garantía, existe una esfera ajena a la praxis humana que posibilita el despliegue de ese bien moral por entre todos los contenidos de la acción social.

La visión de la historia que hemos criticado es fundamento para un uso ideologizado de derechos humanos, pues "[1]os dominadores necesitan sentir que moral e históricamente se justifica que sean el grupo dominante" (Wallerstein, 2007, p. 49). La FL asume otro concepto de historia no sólo como una tarea intelectual, sino también como principio de desideologización, y para darle cabida en la dinámica histórica al sujeto vivo, práxico e intersubjetivo. En este sentido, consideramos que la propuesta de Ignacio Ellacuría, inspirada en la filosofía de Xavier Zubiri, fundamenta otra comprensión de la historia.

\section{EL ANÁLISIS DE LA HISTORIA EN LA FILOSOFÍA DE LA LIBERACIÓN}

Ignacio Ellacuría (2001) señala, siguiendo a Xavier Zubiri, que la historia no es una suprarrealidad, sino unidad dinámica de los individuos y de las realidades que están en curso histórico. La historia no surge, como 
afirmaría Hegel, del Espíritu Absoluto, sino de los individuos personales en cuanto forman cuerpo social, y en cuanto pertenecen a la unidad real de la especie, a un phylum; es decir, no se sustantiviza a la historia, como lo hace Hegel, pero tampoco es compatible con las lecturas marxistas que establecen un proceso de sustantivización de lo histórico, donde los individuos y sus acciones están determinados por el curso de la historia y su estructura dialéctica. Y es que lo esencial de la historia está en que exista una actualización de las posibilidades, más allá de la actuación de las potencias.

La realidad histórica no es, pues, un proceso sustantivizado donde los individuos son meros accidentes de la historia. La intervención del individuo es importante en la historia; que ella tenga su propia estructura, no significa que anule otras realidades ni se identifica con ellas. La historia implica un conjunto sistemático de posibilidades, que en cada momento tiene una altura procesual precisa y frente a la cual las personas se encuentran en una determinada situación, en un espacio y un tiempo. Así, el sujeto se encuentra inmerso también en los condicionamientos naturales que siguen presentes en la historia y en la propia condición individual.

Este concepto de historia amplía el concepto de lo histórico. En principio, nada queda fuera de la historia y todo puede considerarse como histórico, con tal de que pueda convertirse en posibilidad de vida humana. Todo puede convertirse en historia cuando se convierta en posibilidad actualizada como tal.

La historia no está por encima de los individuos, sino por debajo de ellos como resultado de su carácter impersonal. Es decir, la historia no es la que hace formalmente a las personas, sino que son las personas las que hacen la historia. El conjunto de posibilidades de vida ofrecidas es condición real de las opciones personales, y éstas son las que dan su carácter específico a la historia y que la llevan más allá de los condicionamientos y determinaciones naturales. Cuando los procesos históricos tienen un 
carácter a-personal (no impersonal, que es diferente) entonces se debe dejar de hablar de historia, y considerarlo como un puro proceso natural, un proceso de naturalización y de despersonalización (Ellacuría, 2001).

Ellacuría (1999) afirma el carácter material de la historia. La materialidad de la historia no es lo mismo que el materialismo histórico, que si bien lo incluye es sólo uno de sus aspectos. ¿Qué se entiende entonces por materialidad de la historia? Es una forma de comprender su realidad integral, superando el dualismo que señala que la historia es no-naturaleza y la naturaleza es no-historia; esto sería válido como algo diferenciativo y formal pero no en su totalidad real. La historia surge y tiene su fundamento en la naturaleza material y se encuentra indisolublemente enlazada a ella. Sin naturaleza no podría existir la historia, aunque sin historia existiría la naturaleza; la materialidad de la historia significa una presencia de la naturaleza material en la historia. En este sentido, Ellacuría (1999) delimita cuatro momentos básicos de la materialidad de la historia: la materia misma, el espacio, el tiempo y la vida. El tratamiento de cada uno de estos momentos se basa en el pensamiento zubiriano, aunque orientado a conceptualizar la materialidad de la historia.

Además de la materialidad de la historia, Ellacuría toma en cuenta otros dos componentes: lo social y lo personal. En efecto, es un hecho que en la historia intervienen tanto las personas como la sociedad. Sin dejar a un lado la materialidad, desarrolla con amplitud, y en diálogo con diversos autores, qué debe entenderse por sociedad y por persona. Esto es necesario si se acepta cierta dimensión personal y cierta dimensión social de la historia. No se trata de una pretensión por realizar ni una sociología ni una antropología previas al abordaje de la historia, sino sólo destacar algunos caracteres fundamentales de la sociedad y de la persona humanas, con el fin de comprenderlos como componentes de la historia. 
Teniendo como fundamento lo anterior, se construye la realidad formal de la historia $\mathrm{o}$, en otros términos, la manera en que la realización de la realidad humana - tanto social como personalmente - se da históricamente, sin que signifique una idealización que niegue la materialidad o la presencia constante de la naturaleza, y sin pretender establecer un determinismo o una teleología. En efecto, para entrar a establecer qué es la historia en tanto que historia, Ignacio Ellacuría propone abordar su definición real desde tres características: como transmisión tradente, como actualización de posibilidades, y como proceso creacional de posibilidades.

\subsection{La Historia Como Transmisión Tradente}

El cuerpo material de la historia es puesto por el phylum humano a través de su carácter pluralizante, su carácter continuante y su carácter prospectivo. Tanto en la continuidad de la especie como en la sucesión histórica hay transmisión, pero entre ambas tienen importantes diferencias. Para el ser humano, a diferencia del animal, las cosas no son meros estímulos sino realidades; además de que el ser humano está en la realidad y realizándose, autodefiniéndose a sí mismo. Las formas de estar en la realidad no se transmiten de manera genética, pues por esta vía lo transmisible son las estructuras psico-orgánicas que dan la posibilidad, eso sí, de estar radicalmente en la realidad.

El ser humano es introducido a la vida en un peculiar "modo humano" de estar en la realidad. Comienza su vida apoyado en algo más que su propia sustantividad psico-orgánica y el medio biológico que lo rodea; se apoya en una forma de estar en la realidad. Esta manera de entregar la forma de estar en la realidad no se realiza de los generantes solos al generado, sino que al entregarla lo hacen como pertenecientes al cuerpo social. Esta entrega de un modo de estar en la realidad es posible debido a que el ser humano es una esencia abierta: "Toda vida humana comienza así montada sobre un modo de estar en la realidad, que le ha sido entre- 
gado. Sólo se puede entregar algo a una esencia abierta, la cual, por ser sentientemente abierta, necesita que, junto con la transmisión genética, se le entregue una forma de estar en la realidad" (Ellacuría, 1999, p. 496). Por su parte, Zubiri (2006, p. 89) señala que “[e]l modo recibido de estar en la realidad, no en tanto que realidad efectiva, sino en tanto que principio de posibilidad de otros modos de estar en la realidad o de repetir el modo recibido. En esto es en lo que formalmente consiste la tradición.” En este sentido, se puede dar un concepto preciso de historia: en la historia se da una entrega de formas de realidad.

Lo anterior es sólo un primer paso en la comprensión de la historia, pues la tradición de formas de estar en la realidad es el mecanismo por antonomasia de lo histórico; pero no es toda la historia, sino sólo un ingrediente formal de ella. Esto no quiere decir que lo biológico quede a un lado en la historia, pues la constitución biológica de la especie se hace presente en los problemas históricos: "La evolución procede por mutación, sean cualesquiera el origen y la índole de las mutaciones. Pero las formas de estar en la realidad proceden al revés, por invención, porque hay que optar. El proceso histórico no es la prolongación del proceso evolutivo" (Zubiri, 2006, p. 77). La historia tiene una articulación precisa: es tanto transmisión como tradición, aunque la razón formal de lo histórico se encuentra en ésta y no en aquélla. Esto no debe interpretarse como una consideración tradicionalista de la historia, por lo cual Ellacuría habla mejor de "tradicionidad" más que de "tradicionalidad"; la historia no implica una mera recepción sino que también es proyectiva. En el presente histórico, que es el momento real físico de la historia, está el pasado, pero también el futuro. Esta tradición, además, afecta a cada persona, y la afecta en su biografía; pero a la vez es lo que posibilita que haya vida personal y que esta vida pueda ser de cierta forma. Da ahí que la propia vida tenga una dimensión forzosamente histórica, por realizarse en una determinada "tradicionidad". $\mathrm{Al}$ respecto, Zubiri ( 2006, p.76) señala: 
El proceso histórico es concretamente tradición. No en el sentido de ser tradicional, sino en el mero sentido de ser entrega. La vida se transmite genéticamente, pero las formas de estar en la realidad se entregan. Y precisamente por eso, porque es tradición, es por lo que la vida humana no comienza en cero. Comienza siempre montada sobre un modo de estar en la realidad que le ha sido entregada. Y esto es formalmente la historia: tener un modo de estar en la realidad entregado por el progenitor. El carácter prospectivo de la especie es historia precisamente porque afecta a una esencia abierta, la cual produce como descendencia un animal de realidades no simplemente por transmisión genética, sino a una con ella, por una inexorable traditiode formas de estar en la realidad.

La entrega de formas de realidad no se realiza de una vez por todas, sino que se desarrolla a lo largo de toda la vida. Las situaciones concretas le ofrecen al ser humano posibilidades precisas y acotadas de estar en la realidad. De ahí que la opción humana es absoluta en cuanto opción pero no lo es en cuanto a sus contenidos, pues estos están acotados y limitados. Es así que la libertad no es absoluta, sino que las opciones humanas se dan entre posibilidades reales muy precisas. Como estructura que es, la historia tiene diversos momentos: (a) El momento constituyente es aquel que da la forma de estar en la realidad, en la cual se va a instalar el viviente o el grupo humano. Además, los seres humanos y los pueblos constituyen tradición debido a que pueden modular los modos de estar en la realidad sobre lo recibido; (b) El segundo momento, el momento continuante, se basa en que la tradición continúa porque quien recibe la forma de estar en la realidad es una esencia sentientemente abierta. No sólo es continuante porque siga lo recibido, sino porque lo impulsa hacia adelante, lo cambia; por eso, este momento es todo menos repetición: "la repetición en la historia resulta así absolutamente imposible y la fidelidad histórica no puede lograrse más que en la forma del proseguimiento” (Ellacuría, 1999, p. 499); 
(c) El último y tercer momento, el momento progrediente, consiste en que la propia estructura de la tradición empuja hacia delante y lleva al cambio, y es un principio de dinamismo histórico.

Lo anterior nos lleva a considerar el tema de la impersonalidad de la historia. Cuando el individuo está vertido a los demás en tanto que otros, la versión a ellos es impersonal. La línea de lo impersonal es lo que va a definir lo social; se entiende por impersonal los actos o aspectos de la vida personal cuyo carácter personal queda en cierto modo en suspenso. Se trata de las acciones no personales sino tan sólo de la persona. En este sentido, la historia “[e]s un proceso impersonal, en el cual se hacen presentes las personas, pero no reduplicativamente en cuanto tales: lo que ellas vierten sobre la historia es tan sólo el resultado de la vida personal y lo que ellas reciben de la historia puede ciertamente serlo en forma estrictamente personal, pero puede también serlo en forma despersonalizada, cuando el hombre queda apresado y dominado por posibilidades ofrecidas, de modo que éstas, más que como posibilidades históricas, se le puedan llegar a convertir en forzosidades naturales” (Ellacuría, 1999, p. 532).

Lo entregado y recibido en la tradición es social. La tradición afecta a las personas no sólo en lo personal, sino también como cuerpo social; por eso se puede afirmar que es el ser humano social quien se vuelve en sujeto activo y pasivo de la tradición. Lo destacable para la historia es lo que se transmite socialmente, pues, aunque en ella intervengan los individuos, su intervención sólo llega a ser histórica cuando, de un modo u otro, se convierte en social. Pero, hay que considerar que esto no conlleva a la sustantivización del cuerpo social: "Que el cuerpo social sea el sujeto de la tradición social no significa, sin embargo, que sea una especie de nueva macrosustantividad individual, pues las acciones las siguen haciendo los individuos; significa, tan sólo, que los individuos operantes lo hacen como integrantes del cuerpo social, como vinculados en los otros en tanto que otros” (Ellacuría, 1999, p. 505). Este carácter social de la tradición com- 
prende dos principios de impersonalidad: primero, la historia está hecha por lo que queda objetivado de las acciones personales y no por su carácter personal e íntimo; $y$, segundo, la historia está hecha por sujetos integrados en el cuerpo social. La historia no surge sólo de la confluencia de las acciones de los individuos, sino de los individuos en cuanto constituyentes de un cuerpo social, que como tal no se reduce a la suma de los individuos. Esto no deja de lado la necesidad de acciones personales; en la realidad existe una constante influencia entre la persona y la historia. En el marco de lo histórico social cabe una estricta tradición personal de entrega y recepción, y a la vez, las personas y sus acciones transmiten contenidos y realidad al cuerpo social y a la historia (Ellacuría, 1999, p. 506).

Por otra parte, comprendiendo así la historia, el sujeto de la tradición es el phylum. La historia no es una sustantividad que flote sobre los individuos y los grupos humanos, sino que es algo que ocurre en ellos y con ellos; ocurre de forma filética e impersonal aunque sin anular el carácter individual ni el carácter personal. De ahí que Ellacuría considere que el sujeto propio de la historia es el phylum, en cuanto éste forma cuerpo social como ámbito de lo impersonal. Los individuos intervienen en la historia, pero lo que interviene es su producto que entra a formar parte de una estructura, de la cual recibe su sentido real y no de la intención subjetiva con que fue producido. Como señala Zubiri, el sujeto de la historia es el phylum en cuanto tal, y este phylum histórico "puede afectar a o bien a cada uno de los individuos, y constituye entonces su biografía personal, o bien a una sociedad, y entonces tiene este carácter impersonal en el sentido de compuesto por personas que pueden ser únicas, pero que lo son no por el carácter de su persona, sino por aquello que hace y que aportan a la sociedad” (Zubiri, 1995, p. 83).

A través de esta concepción de lo histórico, Ellacuría (1999) busca superar el dualismo entre lo histórico y lo personal, sin que ninguno de los dos pierda su autonomía y formalidad. También busca superar las 
posturas idealistas que desatienden el aspecto filético e impersonal de la historia, como de las materialistas que minimizan el carácter individual y las acciones personales en ella.

En la dimensión histórica tienen cabida tanto la historia social como la biográfica, en virtud de que por el phylum del animal de realidad los miembros de la especie conviven (dimensión social), y por el que hay una tradición prospectiva (dimensión histórica), que ambas pueden presentarse en forma personal o impersonal. La especie y el cuerpo social no anulan la personalidad del individuo, y la historia social no excluye sino más bien reclama la presencia de la historia biográfica, pero en lo que ésta tiene de historia y no en lo que tiene de biografía personal. Hay que tomar en cuenta que de forma paralela lo que ocurre en la historia ocurre formalmente al cuerpo social; y esto condiciona lo que les ocurra a los individuos en cuanto pertenecientes al cuerpo social. Es a los individuos a los que les ocurren cosas y es en ellos por donde pasa el ocurrir histórico, pero es a los individuos que forman un cuerpo social y a los que la pertenencia al cuerpo social les afecta intrínsecamente, a los que les afecta el ocurrir de la historia y lo que en la historia sucede.

\subsection{La Historia Como Actualización de Posibilidades}

La historia, además de ser transmisión tradente de formas de estar en la realidad, también es actualización de posibilidades. El modo de estar en la realidad que se entrega es un modo ofrecido y no impuesto, pues es un sistema de posibilidades no puramente lógicas sino reales, que dan un poder para hacer la propia vida y no imprimen una necesidad fija y unidireccional de realización de dicho poder. El ser humano puede crear posibilidades, pero siempre se apoyará en otras que le han sido entregadas. Pero estas posibilidades no consisten en que estén dadas sino que no hay una conexión necesaria e inmediata entre las posibilidades y las acciones correspondientes, aunque éstas sólo pueden realizarse si han 
sido previamente posibilitadas: "Las posibilidades no dan el poder para optar, pero sí dan el poder optar; el poder para optar es algo que el individuo humano trae consigo, pero para poder optar con ese poder de opción se requieren estrictas posibilidades posibilitantes" (Ellacuría, 1999, p. 512). De ahí que las posibilidades necesiten del poder de opción para pasar a la acción y de ahí a la realización. Por eso, las posibilidades son las que dan paso a la vida humana y a la historia. Posibilidad, desde esta perspectiva, no es lo que cualquier potencia puede hacer, sino aquello que posibilitando positivamente no puede pasar a ser realidad sino por opción.

Como la historia es una estructura, las acciones que se ejecutan en ella no son aisladas sino que les corresponde una posición estructural. Esto define sus límites tanto de su realidad como de su sentido, pero no anula el carácter opcional ni posibilitante de lo histórico. Esto es importante tomarlo en cuenta, pues es en la apropiación y actualización de las posibilidades donde se define el carácter histórico de la acción humana. La apropiación se da cuando a través de la opción se realizan las posibilidades. Toda opción tiene un momento físico de apropiación, y esto hace que la actividad humana de ser un hecho se convierta en un suceso: el suceso es el hecho en tanto realización de posibilidades. Por esto, las actividades humanas, sea cual fuese su índole, tienen un carácter histórico, por tratarse de una realización de posibilidades previamente apropiadas y en las que se han apoyado. La historia se refiere a los modos de estar en la realidad, pero estos modos sólo pasan históricamente a la realidad por apropiación optativa de lo que posibilitan esos modos entregados de estar en la realidad.

El carácter procesual de la historia no está en la continuidad de los hechos, sino en la continuación de los sucesos. Por eso, lo importante de la historia es cómo surge un hecho de sus determinados antecedentes, sino cómo se enlazan las posibilidades; no lo es el catálogo de potencias reales 
sino el elenco de las posibilidades reales de las cuales se puede disponer. Es decir, de las condiciones objetivas para lograr un determinado uso de la naturaleza o una determinada organización social.

Lo dicho anteriormente no significa que la historia sea lo mismo que la sociedad y su dinamismo, pues si bien son inseparables no se identifican, ya que lo formalmente histórico inicia cuando los momentos y los dinamismos de la sociedad se convierten en posibilidades, por muy modesto que sea el carácter de posibilidades con que se presenten y por muy modesto que sea el acto de apropiación, por el cual esas posibilidades pasen a ser realidades optadas. El dinamismo de la historia es, en dicho sentido, un dinamismo de posibilitación. Se trata de la entrega de formas de vida real, que se convierten para el ser humano en posibilidades de realización tanto biográfica como social.

\subsection{La Historia como Proceso Creacional de Posibilidades}

Desde la actualización de posibilidades, la realización histórica puede considerarse como una cuasi-creación. Se trata de creación porque se llevan a cabo acciones desde unas posibilidades y unas capacidades que a su vez ya han sido actualizadas previamente; es una creatividad histórica, pues se crea desde algo dado, pero que requiere del ser humano en su apertura a lo real y por encima de los condicionamientos naturales. Se da una verdadera producción de algo que realmente no era aún, es decir, de capacidades. Existe un aumento constante de posibilidades, un enriquecimiento y complicación del sistema de posibilidades. Son posibilidades nuevas que no eran tales ni de manera germinal, ni veladamente, debido a que ni siquiera eran "posibles" realmente.

La historia del ser humano, entonces, se realiza a sí mismo actualizando sus propias capacidades; de ahí que la capacitación es un proceso por el que se va incorporando al sujeto en cuestión un poder posibilitar. 
No es un poder absolutamente libre porque está en función de lo que admitan potencias y facultades así como de lo ofrecido en cada caso por la realidad como raíz y ámbito de posibilidad. De ahí que sólo sea verdadera y formalmente histórico aquello que surja a la realidad por actualización procesual de posibilidades:

[E]1 aire con su carácter de naturaleza es hoy una posibilidad histórica actualizada por el proceso de capacitación que la humanidad ha ido teniendo, es una posibilidad de vuelo, sin que haya cambiado para nada su estructura potencial y física. Y es que la nuda realidad, sin cambiar la estructura de sus notas, puede, no por sí misma, pero sí desde sí misma, ofrecer distintas posibilidades, que se constituyen como posibilidades no solo para un sujeto histórico, sino por la procesual capacitación de ese sujeto histórico (Ellacuría, 1999, p. 554).

El proceso histórico es abierto porque al ser humano no le son dadas de una vez todas las posibilidades. La novedad histórica radica en la historia misma como proceso productor y del sujeto de esa historia, que tiene reales capacidades que antes no tenía. Y es que la actualización de las posibilidades entregadas impulsa al ser humano hacia la constitución de otras, hasta crear un nuevo sistema de posibilidades. Ellacuría insiste que el carácter creativo de la historia radica formalmente en las capacidades que el ser humano va adquiriendo a través del proceso y que le otorgan un mayor poder creacional y de actividad transformadora.

El que la historia sea un proceso creacional de capacidades nos lleva a una conclusión sumamente importante: lo histórico no es maduración de lo que estaba en germen ni develación de lo que estaba oculto. No cabe aquí la interpretación aristotélica de la potencia-acto, ni teleológica o idealista, que tanto ha dominado en la filosofía de la historia. Como ejemplifica Zubiri (1995, p.87) "todo lo que distingue al hombre de Cromagnon tenía probablemente las mismas potencias que el hombre de hoy, pero tenía un sistema de posibilidades distinto en virtud del cual el hombre de hoy puede viajar en avión y el hombre de Cromagnon no podía hacerlo”. 


\section{CONCLUSIÓN}

El concepto de historia que propone Ellacuría, en estrecha conexión con el pensamiento de Zubiri, permite denunciar las agresiones contra pueblos y culturas que han solido justificarse, en parte, por las filosofías teleológicas e idealistas de la historia.

Los derechos humanos se presentan en muchas ocasiones, como hemos insistido, en elementos de esta ideología. Se utilizan para establecer la única racionalidad válida para el desarrollo y progreso en la historia; lo que nos lleva a caer en una inversión ideológica ya que "la mayor violación que existe contra los derechos humanos consiste en impedir a una cultura, a un grupo o a determinados individuos dentro de sus grupos y/o culturas, que puedan reivindicar su idea de dignidad, sea impidiéndoselo por norma o no creando las condiciones para su respeto y puesta en práctica” (Herrera Flores, 2000, p. 63). Bajo esta perspectiva, derechos humanos no son instrumentos para las praxis de liberación de las comunidades de victimizados, sino instrumentos de una ideología que aboga por el fin de la historia, buscando eternizar las relaciones sociales hegemónicas, y a soslayar las causas reales y materiales que generan constantemente luchas de liberación en la historia.

El pensamiento hegemónico de Occidente no evalúa honradamente su pasado ni su progreso. Si no fuera por las consecuencias que esto conlleva, parecería que hay una carga de inocencia. Ellacuría (2000, p. 268) critica a los teóricos del "progreso" porque enfocan "la cuestión sin percatarse que el 'progreso' es una abstracción.” La idea de derechos humanos sufre de esto, en especial cuando se utiliza su historiografía como un instrumento ideológico para justificar el capitalismo, presentándolo como "un capitalismo bueno", que con el paso del tiempo y la expansión de los derechos (primera, segunda, tercera generaciones...) se ha vuelto "menos salvaje" y se ha "humanizado". Esto justifica la imposición y la discriminación, pues como señala Helio Gallardo, "el fondo de esta discusión es la 
crítica de las nociones de 'progreso’ y ‘desarrollo’ en cuanto indicadores ideológicos de una filosofía de la historia que permite discriminar seres humanos: a quienes se oponen a este progreso (indígenas y pueblosculturas atrasados), a quienes lo alternativizan (socialistas, comunistas, utópicos, luchadores por la paz, etc.) o a quienes son identificados como 'enemigos' (terroristas, comunistas, portadores de sentimientos atávicos o tribales como el reclamo de solidaridad, críticos del 'progreso', etc.) y tratarlos como objetos y cosas" (Gallardo, 2006, p. 167).

Dicha forma de ver la dinámica histórica de derechos humanos está influenciada por la filosofía de la historia de la Modernidad. En este contexto, derechos humanos son concebidos como productos racionales que desde su nacimiento formal en las luchas burguesas del siglo 18 tienen contenidos en sí mismos todo lo que han de dar; lo único que se necesita es que pasen de la potencia al acto a través de la historia. Así se lee la historia como un proceso lineal sin contradicciones de fondo: los derechos sociales no son considerados como la afirmación de un sector que se veía explotado por aquellos sectores que se habían empoderado a través de la afirmación de los derechos liberales, ni los derechos culturales y de los pueblos se comprenden como el empoderamiento de los pueblos a quienes el colonialismos -y ahora el neocolonialismo- les había negado su dignidad. ${ }^{4}$ Se invisibilizan las praxis de liberación y los seres humanos concretos que buscan modificar las tramas de poder para lograr un mejor acceso a los bienes necesarios para satisfacer sus necesidades para la producción y reproducción de vida. Hemos visto cómo se afirma que se tratan tan sólo de procesos contenidos en la propia naturaleza o en la racionalidad

${ }^{4}$ Aunque cabe señalar que hay visiones de los derechos humanos que aún reconociéndolos como resultados de estas contradicciones y de procesos dialécticos, siguen manteniendo de fondo la visión teleológica, progresista, de la historia. Esto en gran parte porque la visión teleológica puede ir separada de la visión idealista. 
de los derechos, y la historia se da como despliegue a través de procesos de generalización, de positivización y de especificación de los mismos derechos originados en el siglo 18 por las revoluciones burguesas.

Lo que se termina sosteniendo, desde el esquema teleológico e idealista de la historia, es que el sujeto de los derechos humanos es el ser humano en abstracto, trátese de los derechos liberales, de los derechos sociales o de los derechos culturales, y se relega la importancia de la praxis y la creatividad del sujeto corporal y vivo, y de las comunidades concretas de vida, para comprender la dinámica histórica. Paradójicamente, este liberalismo del sujeto abstracto termina siendo funcional al totalitarismo del mercado, pues desde la manera en que está estructurado el actual sistema-mundo, y considerando la materialidad de la historia, la única libertad plena es quien pueda ejecutarla como libertad en el mercado.

Por medio de dicho humanismo abstracto se inscribe a derechos humanos en una instancia suprahumana, semejante al Espíritu Absoluto de Hegel. Al contrario, como hemos visto, la historia es entendida por la FL desde la praxis humana y los conceptos de capacitación y posibilitación. Es el ser humano en su integralidad, a través de la praxis histórica, quien toma sobre sus hombros el hacerse cargo de la realidad. Esto guarda relación con la siguiente afirmación de Zubiri (1995, p. 165): “No es la persona para la historia, sino la historia para la persona. La historia es la que es absorbida en y por la persona; no es la persona absorbida por la historia”. De ahí el rechazo a colocar a derechos humanos fuera de la materialidad de la historia, sin que esto signifique un acotamiento a la creatividad humana.

Es importante señalar que, como muestra José Sols Lucia (1999), el concepto zubiriano de "posibilitación” guarda relación con el de "praxis" utilizado por Ellacuría. Para Zubiri (1995), la posibilitación se funda no en la nuda realidad sino en la realidad-sentido; con lo cual cualquier dinamismo de posibilitación hace más suya a la realidad humana ya que se 
constituye desde sí misma con las cosas y, por lo tanto, toda posibilitación se funda en la autoposesión de las personas. Ellacuría asume esta perspectiva pero va más allá, al considerar que no todo proceso de posibilitación se constituye en una verdadera praxis de transformación. La dirección del proceso histórico no está determinado naturalmente, y no cualquier conjunto de opciones va a dar lo más pleno de la realidad. Desde la situación sociopolítica que reflexiona Ellacuría - y en general la FL -, le es claro, ante la realidad histórica marcada por la injusticia, la exclusión y la opresión, que no se puede concebir un progreso histórico de forma optimista e idealista. Tras esta constatación es necesario pasar de la mera posibilitación a la praxis, para asumir la tarea de construir la verdad de la realidad; la verdad de la realidad no es lo ya hecho, sino que el ser humano debe volverse a lo que está haciendo y a lo que está por hacer. Sin olvidar que el ser humano está abierto a la realidad, y al hacerse cargo de ella, muestra que las posibilidades para abrirse y "cuasi-crear" algo nuevo.

La realidad histórica no se predice, sino que se produce, se crea a partir de la praxis humana sobre la base del sistema de posibilidades determinado por cada situación y momento del proceso histórico. En la historia no están dadas todas las posibilidades de una vez por todas, sino que la actualización de esas posibilidades empuja al ser humano a la constitución de otras, incluso a la creación de un nuevo sistema de posibilidades. Por eso, es importante reconocer la pluralidad de la praxis como característica de la dinámica histórica, pues es así como el ser humano se hace cargo de la realidad y actúa sobre ella para transformarla (Ellacuría, 1999).

La praxis no es reducible a la naturaleza o a la razón, pues la historia es algo que va dando de sí misma. Pero nada nos asegura que la apropiación de posibilidades sea la más adecuada para la instauración de la justicia, de humanización y personalización. Recuérdese que la historia es la que está en juego por la apropiación de unas u otras posibilidades, apropiación que va a suponer la existencia de unas capacidades y la no 
existencia de otras. Por eso, la praxis no es liberadora en sí misma. El ser humano se va configurando históricamente en virtud de las posibilidades que en cada momento recibe y se apropia. En este sentido, la realidad histórica puede ser principio de libertad, humanización y liberación, pero también de alineación, dominación y opresión.

La comprensión materialista de la historia nos lleva a asumir, más allá del liberalismo abstracto, la auténtica dinámica de la conquista de derechos humanos. Ésta no se da por una expansión de la racionalidad de los derechos o en virtud de una naturaleza humana; sino que se realiza en virtud del sujeto vivo, intersubjetivo y práxico que en el proceso histórico se apropia de posibilidades y capacidades:

Podría decirse que el liberalismo [...] busca ofrecer igualdad de oportunidades para todos los individuos y todas las tendencias. Pero de hecho esto no es así y el más mínimo ejercicio de historización muestra que las libertades y sus condiciones no se regalan, sino que se conquistan en un proceso histórico de liberación (Ellacuría, 1993, p. 417).

La historia es concebida, desde esta perspectiva, como un proceso discontinuo y sometido a retrocesos y estancamientos, de adquisición de capacidades por parte del sujeto humano, y de actualización de posibilidades en la realidad social e histórica. Este proceso no se presenta como algo necesario, con lógica interna o con un telos que marque la superioridad moral de una civilización o cultura. Se trata de un proceso contingente, frágil y sometido a pérdidas y retrocesos. La historia es siempre un proceso creativo y abierto: "El destino de la historia es algo que la historia se va dando a sí misma: se va dando sus propias posibilidades, se va dando sus propias capacidades (...) y se van dando -o al menos se puede llegar a dar- su propia figura histórica” (Ellacuría, 1993, p. 561). En este sentido, lo que define una época histórica es la altura procesual, es decir, el determinado sistema de posibilidades que en el proceso de la realidad histórica condiciona el carácter de las acciones humanas. 
Esta concepción de la historia es más apta para comprender la dinámica histórica de derechos humanos. Si la historia "no es simplemente transmisión de vida, no es simple herencia, sino transmisión de una vida que no puede ser vivida más que en formas distintas de estar en la realidad" (Zubiri, 1995, p. 75), entonces los derechos deben comprenderse no como elementos ajenos a un modo de estar en la realidad. La actualización y apropiación de posibilidades, y la creación de capacidades, es el marco desde el que comprendemos la dinámica histórica de derechos humanos desde las praxis de liberación. No estamos ante una cuestión que pueda comprenderse adecuadamente a través de afirmar un proceso de generaciones o de expansión y despliegue de una racionalidad, sino que los derechos humanos se ubican en distintas alturas procesales debido a que la praxis humana responde a problemas y racionalidades diversas (Sánchez Rubio, 2010). De ahí que ubicar, por ejemplo, los derechos culturales de los pueblos como derechos de "tercera generación” o producto de un "proceso de internacionalización" es invisibilizar -y por lo tanto también desperdiciar- las luchas históricas generadas fuera del ámbito eurocéntrico.

Por otro lado, la clásica división en "generaciones” puede ser leída críticamente desde esta visión de la historia. Si desechamos las perspectivas que la muestran como una racionalidad a la que la historia responde -una racionalidad que justifica a las víctimas del "progreso"-, entonces nos ayuda a tomar conciencia de que los derechos humanos no son algo estático, sino dinámico en el seno mismo del Occidente, y que son productos de conflictos y surgimientos constantes de nuevos sujetos intersubjetivos, de comunidades de victimizados que realizan praxis de liberación en búsqueda de modificar las tramas de poder para acceder a los bienes que les permitirán producir, reproducir y desarrollar su vida. 
A partir de lo analizado en este apartado, el concepto de "progreso" debe rechazarse, pues como lo ha entendido la Modernidad es una abstracción que justifica la generación de víctimas por parte de los sistemas. Ellacuría señala que éste “es, efectivamente, una abstracción. Prescinde o ignora - para el caso práctico es lo mismo - que la multitudinaria y gravísima realidad del tercer mundo se presenta realmente en su concreto conjunto total en términos de revolución” (Ellacuría, 2000, p. 268). Es decir, subvertir la lógica de la civilización de la riqueza hace necesario hablar de revolución más que de progreso:

La revolución que se necesita, la revolución necesaria, será aquella que pretenda la libertad desde y para la justicia y la justicia desde y para la libertad, la libertad desde la liberación y no meramente desde la liberalización, sea ésta económica o política, para superar así el 'mal común' dominante y construir un 'bien común', entendido éste en contraposición de aquél y procurado desde una opción preferencial por las mayorías populares (Ellacuría, 1993, p. 435).

Comprender la dinámica de los derechos humanos desde la concepción de historia que propone Ellacuría, posibilita superar la falacia desarrollista y el eurocentrismo. Conlleva a comprender que derechos humanos responden a procesos de praxis históricas de liberación, donde se dan la apropiación de posibilidades y la generación de capacidades. Por eso, se rechaza una única línea histórica, sino diversas alturas procesales donde, desde diferentes racionalidades y realidades, se generan distintas demandas y reivindicaciones de las comunidades de victimizados en búsqueda de posibilitar la producción, reproducción y desarrollo de su vida. La dinámica histórica de los derechos no responde a generaciones que se complementan entre sí, ni a la expansión de la racionalidad interna de un concepto, sino a la posibilitación y generación de capacidades que la praxis histórica de liberación de los pueblos pueda dar de sí. 


\section{REFERENCIAS}

AMIN, Samir. El eurocentrismo. Crítica de una ideología. México: Siglo XXI, 1989.

BENJAMIN, Walter. Tesis sobre la historia y otros fragmentos. Trad. Bolívar Echeverría. México: Ítaca UACM, 2008.

BRAUER, Daniel. La filosofía idealista de la historia. In: MATE, Reyes (Ed.). Filosofía de la historia. Madrid: Trotta, 2005.

ELLACURÍA, Ignacio. Persona y comunidad. Escritos filosóficos. San Salvador: UCA Editores, 2001. Tomo III.

ELLACURÍA, Ignacio. Progreso y revolución. Escritos teológicos. San Salvador: UCA Editores, 2000. Tomo I.

ELLACURÍA, Ignacio. Utopía y profetismo. Mysterium Liberationis. Conceptos fundamentales de la teología de la liberación. San Salvador: UCA Editores, 1993. Tomo I.

ELLACURÍA, Ignacio. Filosofía de la realidad histórica. San Salvador: UCA Editores, 1999.

GALLARDO, Helio. Siglo XXI. Producir un mundo. San José de Costa Rica: Editorial Arlekín, 2006.

GONZÁLEZ, Antonio. Ignacio Ellacuría Filósofo: Su relación con Zubiri. In: LARREA, Juan; ELLACURÍA, Ignacio. Vascos universales del siglo XX. Madrid: Biblioteca Nueva, 2005.

HEGEL, G. W. F. Enciclopedia de las ciencias filosóficas. Trad. E. Ovejero y Maury. México: Porrúa, 1997.

HEGEL, G. W. F. Filosofía del derecho. Trad. Angélica Mendoza de Montero. México: Casa Juan Pablos, 2004.

HEGEL, G. W. F. Lecciones sobre la filosofía de la historia universal. Trad. José Gaos. Buenos Aires: Revista de Occidente, 1946. Tomo I. 
HERRERA FLORES, Joaquín. Hacia una visión compleja de los derechos humanos. El vuelo de Anteo. Derechos humanos y crítica a la razón liberal. Bilbao: Desclée de Brouwer, 2000.

HERRERA FLORES, Joaquín. Los derechos humanos como productos culturales. Crítica del humanismoabstracto. Madrid: Catarata, 2005.

KANT, Immanuel. Idea de una historia universal en sentido cosmopolita. Filosofía de la historia. Trad. Eugenio Ímaz. México: FCE, 1997.

MATE, Reyes. Medianoche en la historia. Comentarios a las tesis de Walter Benjamin "Sobre el concepto de historia”. Madrid: Trotta, 2009.

PECES-BARBA, Gregorio. Curso de derechos fundamentales. Teoría general. Madrid: Universidad Carlos III de Madrid - BOE, 1999.

PÉREZ LUÑO, Antonio Enrique. Las generaciones de derechos fundamentales. Revista del Centro de Estudios Constitucionales, n. 10, sep./dic. 1991.

PÉREZ LUÑO, Antonio Enrique. Derechos humanos, estado de derecho y constitución. Madrid: Tecnos, 2005.

RIST, Gilber. El desarrollo: historia de una creencia occidental. Trad. Adolfo Fernández. Madrid: Catarata-UCM, 2002.

ROSILLO MARTÍNEZ, Alejandro. Presupuestos para recuperar la tradición hispanoamericana de derechos humanos. Crítica Jurídica, Unam-Universidad de Buenos Aires; Fundación Iberoamericana de Derechos Humanos, n. 29, enero-junio 2010.

ROSILLO MARTÍNEZ, Alejandro. Los inicios de la Tradición Iberoamericana de Derechos Humanos. San Luis Potosí; Aguascalientes: UASLP; Cenejus, 2011.

SÁNCHEZ RUBIO, David. En torno a la historización y las generaciones de derechos humanos. In: ELLACURÍA, Ignacio. 20 años después. Actas del Congreso Internacional. Sevilla: Instituto Andaluz de Administración Pública, 2010.

SANTOS, Boaventura de Sousa. Crítica de la razón indolente. Contra el desperdicio de la experiencia, Bilbao: Desclée de Brouwer, 2000. 
SANTOS, Boaventura de Sousa. El milenio huérfano. Ensayos para una nueva cultura política. Madrid: Trotta, 2005.

SOLS LUCIA, José. La teología histórica de Ignacio Ellacuría. Madrid: Trotta, 1999.

WALLERSTEIN, Immanuel. Universalismo europeo. El discurso del poder. México: Siglo XXI, 2007.

ZUBIRI, Xavier. Estructura dinámica de la realidad. Madrid: Alianza EditorialFundación Xavier Zubiri, 1995.

ZUBIRI, Xavier. Tres dimensiones del ser humano: individual, social, histórica. Madrid: Alianza Editorial; Fundación Xavier Zubiri, 2006.

Recebido em: 7/11/2012

Aprovado em: 26/11/2012 